\title{
Depressive Symptoms among Latino Sexual Minority Men and Latina Transgender Women in a New Settlement State: The Role of Perceived Discrimination
}

\author{
Christina J. Sun, ${ }^{1}$ Alice Ma, ${ }^{2}$ Amanda E. Tanner, ${ }^{2}$ Lilli Mann, ${ }^{3}$ Beth A. Reboussin, ${ }^{3}$ \\ Manuel Garcia, ${ }^{3}$ Jorge Alonzo, ${ }^{3}$ and Scott D. Rhodes ${ }^{3}$ \\ ${ }^{1}$ OHSU-PSU School of Public Health, P.O. Box 751, SCH, Portland, OR 97207-0751, USA \\ ${ }^{2}$ University of North Carolina, Greensboro, P.O. Box 26170, Greensboro, NC 27402-6170, USA \\ ${ }^{3}$ Wake Forest School of Medicine, Medical Center Boulevard, Winston-Salem, NC 27157, USA \\ Correspondence should be addressed to Christina J. Sun; christina.sun@pdx.edu
}

Received 14 May 2016; Accepted 17 August 2016

Academic Editor: Janusz K. Rybakowski

Copyright (c) 2016 Christina J. Sun et al. This is an open access article distributed under the Creative Commons Attribution License, which permits unrestricted use, distribution, and reproduction in any medium, provided the original work is properly cited.

\begin{abstract}
Background. Little is known about the role of discrimination on depression among Latino sexual and gender identity minorities. This manuscript examined the relationship between ethnic/racial discrimination and sexual discrimination on clinically significant depressive symptoms among Latino sexual minority men (i.e., gay and bisexual men and other men who have sex with men) and Latina transgender women. Methods. A community-based participatory research partnership recruited participants $(N=$ 186; $80.6 \%$ cisgender men) in North Carolina to a social network-based HIV intervention. Using baseline data, we quantified the amount of perceived discrimination and conducted mixed-effects logistic regression analyses to examine correlates of clinically significant depressive symptoms. Results. A high percentage of participants reported ethnic/racial discrimination (73.7\%) and sexual discrimination (53.8\%). In the multivariable models, ethnic/racial discrimination, sexual discrimination, masculinity, fatalism, and social support were significantly associated with clinically significant depressive symptoms. Discussion. Improving mental health requires multilevel interventions that address pertinent individual, interpersonal, and system level factors.
\end{abstract}

\section{Introduction}

The Latino population is rapidly growing in the United States (US) and the South, particularly North Carolina (NC), has become an important new settlement region for immigrant Latinos [1]. Between 2000 and 2010, the Latino population increased by $57.3 \%$ in the South and more than double in NC [2]. Almost half of the Latino population in NC is foreignborn, with Mexico as the predominant country of origin [3]. Immigrant Latinos experience multiple barriers to health (e.g., language, isolation, and documentation status), which can increase the risk for negative health outcomes, including depression, and are exacerbated by a lack of bilingual and bicultural services in new settlement states [4].

The intersection of other identities (e.g., sexual and gender) can compound health risks [5]. Specifically, immigrant Latino sexual minorities may face an increased burden of health. Those who identify as sexual and gender identity minorities can include gay-identified persons, men who have sex with men (MSM) but who do not self-identify as gay, and gender variant/minority or transgender men (e.g., female-tomale transgender). Latino sexual minorities may be particularly vulnerable to mental health disparities. Among immigrant Latino sexual minority men residing in the South, US, Rhodes and colleagues [6] estimated the prevalence of clinically significant depressive symptoms to be between $69.2 \%$ and $74.8 \%$.

Negative mental health outcomes can be affected by perceived discrimination, defined as a behavioral manifestation of negative attitudes, judgment, or unfair treatment toward members of a particular group [7]. Perceived discrimination, structural, institutional, and individual, can generate multiple stressors that adversely affect health [8]. For instance, discrimination is associated with psychological (e.g., emotional 
stress) and physiological (e.g., increased vulnerability to illness) distress $[7,9,10]$. The manifestation of depressive symptoms from discrimination-related stressors may be especially poignant for ethnic/racial and sexual minorities compared to their nonminority counterparts $[11,12]$. Indeed, the burden of poor mental health associated with perceived ethnic/racial discrimination among Latinos may be further complicated by their sexual identity and orientation and gender identity $[9,13,14]$.

Despite much extant literature on the association between perceived discrimination and mental health, limited research is available for sexual minority men and transgender women (exceptions [15-18]). The research that does exist suggests that, in general, perceived discrimination is associated with higher psychological distress (e.g., depression, anxiety, and suicidal ideation) $[7,9]$. Existing studies have predominantly compared the experiences of Latinos in general to other races/ethnicities (e.g., African American/Black [19-21], in metropolitan areas [22-24], or in border states [25, 26]). Few studies have focused on the perceived discrimination experiences of immigrant Latino sexual minority men and Latina transgender women residing in the South; Latinos in new settlement states in the South may be differentially impacted by the lack of infrastructure to meet the unique needs and priorities of this emerging population (e.g., lack of bilingual and bicultural services, including mental health services) and the high levels of anti-immigration sentiment [3, 27-29]. Latinos living in the South, particularly if they are undocumented, may be concerned about the level of confidentiality and privacy available at mental healthcare facilities. If they perceive a lack of Latino-friendly services and recognize high anti-immigration sentiment in the community, they may be hesitant to access and engage in mental healthcare.

Given our focus on the experience of depression among Latino sexual and gender identity minorities, the conceptual framework for this study is the minority stress model [30-32]. This model posits that discrimination, stigma, and prejudice create a hostile and stressful environment that contribute to mental health issues. It identifies a variety of stress processes, including the experience of prejudice events, homophobia, and coping behaviors. This minority stress is particularly salient among sexual minorities compared to their heterosexual counterparts; in fact, the development of this model was motivated in part from observing this higher prevalence and seeking to understand it [32]. Based on the minority stress theory, sexual minority health disparities may be explained in part by a hostile, homophobic environment that then affects mental health [30]. We used the minority stress model to undergird our understanding of the relationship between perceived discrimination and depression among this population, as well as informing the development of our analysis. The purpose of this analysis was to examine the association between ethnic/racial discrimination and sexual identity or same-sex sexual behavior discrimination experienced by Latino sexual minority men and Latina transgender women on depression. Our specific aims were to quantify the amount of perceived discrimination based on ethnicity/race (hereafter ethnic/racial discrimination) and sexual identity or same-sex sexual behavior (hereafter sexual discrimination) experienced by Latino sexual minority men and Latina transgender women and then examine the association between reported discrimination and depression.

\section{Methods}

2.1. Participants and Data Collection. We examined HOLA intervention baseline survey data collected from November 2011 to July $2012[33,34]$. Briefly, the HOLA intervention is a lay health advisor and social network intervention designed to increase HIV testing and condom use among immigrant adult Latino sexual minority men and Latina transgender women. Twenty-one individuals were recruited to serve as lay health advisors; each lay health advisor then recruited 8 Latino sexual minority men and Latina transgender women from his or her social network $(N=186)$. The intervention and evaluation plans were developed in response to community-identified needs and priorities by a communitybased participatory research (CBPR) partnership, comprised of lay community members, organization representatives, and university health professionals and researchers, that has existed for more than 13 years [35]. The study protocol was approved by the Wake Forest School of Medicine Institutional Review Board.

\subsection{Measures}

2.2.1. Demographic Characteristics. Participants reported their age, gender identity (female, male, male-to-female transgender, female-to-male transgender, and other), length of time they had lived in the US, highest level of education (dichotomized as less than a high school diploma or equivalent [GED] or at least a high school diploma or equivalent [GED]), employment status (dichotomized as employed yearround or not), and monthly income (dichotomized as less than $\$ 2,000$ or at least $\$ 2,000$ ).

2.2.2. Alcohol Use. Participants reported the number of days they get drunk in a typical week. This single question has been shown to be an effective measure to assess alcohol use that is associated with higher risk for injury [36].

2.2.3. Acculturation. Participants completed the Short Acculturation Scale for Hispanics [37]. This scale consists of three factors: language use, media, and ethnic social relations or socialization. For example, participants answered the question "What language(s) do you usually speak with your friends?" using the responses "Only Spanish," "More Spanish than English," "Both equally," "More English than Spanish," and "Only English." The Cronbach's alpha for the entire scale in this sample was 0.87 .

2.2.4. Masculinity. Participants rated their agreement to items from the Conformity to Masculinity Norms Inventory [38], a scale developed to measure how strongly someone adhered to traditional masculine gender norms on a 4-point scale from "strongly disagree" (1) to "strongly agree" (4). While the CBPR partnership recognized and appreciated the psychometric properties and comprehensiveness of the 
original 144-item Conformity to Masculinity Norms Inventory that consists of 11 subscales, such as power over women, primacy of work, and disdain for homosexuals, the partnership was concerned about the participant burden. To reduce participant burden, members of the CBPR partnership reviewed all the items and decided to choose items that would be most salient and meaningful to the participants (e.g., Taking dangerous risks help me to prove myself). This process resulted in the selection of 26 items and was found to be reliable (Cronbach's alpha $=0.83$ ).

2.2.5. Internalized Homonegativity. Participants completed the shortened version of the Reactions to Homosexuality Scale [39]. Participants rated their agreement to 7 statements (e.g., Even if I could change my sexual orientation, I wouldn't.) on a 7-point scale from "strongly disagree" (1) to "strongly agree" (7). Cronbach's alpha was 0.83 .

2.2.6. Fatalism. Participants completed a previously validated and reliable fatalism scale [40]. This scale consists of three factors: predetermination, luck, and pessimism. Participants rated their agreement to 20 statements (e.g., If someone is meant to get a serious disease, it doesn't matter what they do, they will get that disease anyway.) on a 5-point scale from "strongly disagree" (0) to "strongly agree" (4). Cronbach's alpha was 0.92 .

2.2.7. Community Attachment. Participants rated their attachment to the gay community, Latino community, and Latino gay community on a 6-point scale from "not at all" (0) to "to a great extent" (5). The three items (e.g., Please indicate how much you feel a part of or connected to the Latino community.) were based on a previously used measure [41]. Cronbach's alpha was 0.88 .

2.2.8. Social Support. Participants completed the 18-item Index of Sojourner's Social Support $[42,43]$. For each item, participants reported how many people would provide socioemotional support (e.g., comfort you whenever you feel homesick) and/or instrumental support (e.g., provide necessary information to help orient you to your new surroundings) on a 5-point scale from "no one would do this" (0) to "many people would do this" (4). Cronbach's alpha for the entire scale was 0.95 .

2.2.9. Discrimination. We measured ethnic/racial discrimination and sexual discrimination using a modified version of the Everyday Discrimination Scale [44]. This measure has been previously validated across ethnic/racial groups [45]. Participants reported in the past 12 months whether they had experienced 10 different types of discrimination (e.g., treated with less courtesy than other people) because of their race, ethnicity, or color (ethnic/racial discrimination) and because of their sexual identity or same-sex sexual behavior (sexual discrimination) with a "yes" or "no" response. We summed the number of "yes" responses such that higher scores reflect greater experiences of discrimination. In this sample, Cronbach's alpha for ethnic/racial discrimination was 0.83 and that for sexual discrimination was 0.81 . The correlation between the discrimination measures was 0.71 .

2.2.10. Depressive Symptoms. Participants completed the widely used Center for Epidemiologic Studies Depression Scale (CES-D) [46]. Participants rated how often they experienced 20 symptoms (e.g., poor appetite, restless sleep, and feeling lonely) associated with depression during the past week on a 4-point scale ("rarely or none of the time, $<1$ day" [1], "some or a little of the time, 1-2 days" [2], "occasionally or a moderate amount of time, 3-4 days" [3], and "most or all of the time, 5-7 days" [4]). In accordance with standard scoring practice for the CES-D, participants who scored 16 or higher on the scale were classified as experiencing clinically significant depressive symptoms [47].

2.3. Analysis Plan. In the case of missing item-level data for a particular scale, if an individual was missing less than $20 \%$ of the items, person mean substitution was used; we replaced missing responses with that individual's mean response [48]. We calculated means, standard deviations, ranges, frequencies, and percentages to describe the sample. We performed bivariable mixed-effects logistic regression analyses to examine the relationship between demographic characteristics, psychosocial characteristics, behaviors, and perceived discrimination with clinically significant depressive symptoms. We then entered variables that were associated with clinically significant depressive symptoms $(p<0.25)$ into the multivariable mixed-effects logistic regression model to identify the independent contribution of each while adjusting for the effects of the other variables in the model; this is a standard approach to model building [49]. Because of the high correlation between ethnic/racial discrimination and sexual discrimination, two separate multivariable models were fit. As transgender women may differentially interpret the items for sexual discrimination (i.e., perceive themselves engaging in heterosexual behaviors), we conducted a subset analysis in which only cisgender men were included. All analyses were conducted in Stata version 12 and mixed-effects logistic regression analyses were conducted using the statistical procedure GLLAMM.

\section{Results}

3.1. Participant Characteristics. On average, participants were 30.1 years and had lived in the US for 10.1 years. Most of the sample identified as male (80.6\%); $0.5 \%$ as female; $17.7 \%$ as male-to-female transgender; and $1.1 \%$ as transvesti. Nearly half $(46.8 \%)$ had a high school diploma or equivalent. Nearly three-quarters $(71.0 \%)$ were employed year-round; however, only one-fifth $(19.9 \%)$ earned a monthly income of at least $\$ 2,000$. Over one-third (37.6\%) met the criterion for clinically significant depressive symptoms. Table 1 summarizes participant characteristics.

Nearly three-quarters of the sample reported experiencing at least one type of ethnic/racial discrimination $(73.7 \%)$ in the past 12 months and over half reported experiencing at least one type of sexual discrimination (53.8\%) in the past 
TABLE 1: Participant characteristics.

\begin{tabular}{lc}
\hline & $\mathrm{M} \pm \mathrm{SD}$ (range) or $n(\%)$ \\
\hline Age (years) & $30.1 \pm 7.2(18-61)$ \\
Length of time living in the US (years) & $10.1 \pm 5.4(0.3-26.6)$ \\
$\geq$ HS diploma or equivalent & $87(46.8)$ \\
Employed year-round & $132(71.0)$ \\
$\geq \$ 2,000$ monthly income & $37(19.9)$ \\
Alcohol use (days/week) & $0.8 \pm 0.9(0-4)$ \\
Acculturation & $2.1 \pm 0.7(1-4.5)$ \\
Masculinity & $52.3 \pm 9.0(30-78)$ \\
Internalized homonegativity & $36.4 \pm 9.1(12-49)$ \\
Fatalism & $44.1 \pm 15.0(20-88.1)$ \\
Community attachment & $12.0 \pm 4.3(3-18)$ \\
Social support & $55.9 \pm 17.1(18-90)$ \\
Ethnic/racial discrimination & $3.0 \pm 2.7(0-10)$ \\
Sexual discrimination & $2.0 \pm 2.5(0-8)$ \\
Clinically significant depressive & $70(37.6)$ \\
symptoms (CES-D $\left.{ }^{\mathrm{a}} \geq 16\right)$ & \\
\hline
\end{tabular}

${ }^{\mathrm{a}} \mathrm{CES}-\mathrm{D}=$ Center for Epidemiologic Studies Depression Scale.

12 months. A higher percentage of participants reported ethnic/racial discrimination compared to sexual discrimination.

3.2. Correlates with Depressive Symptoms. The bivariable modeling shows age, employment status, masculinity, fatalism, and social support were significantly associated with clinically significant depressive symptoms (see Table 2). Both ethnic/racial discrimination and sexual discrimination were significantly associated with increased odds of clinically significant depressive symptoms. In the multivariable models, after adjusting for age, employment status, masculinity, fatalism, and social support, ethnic/racial discrimination and sexual discrimination were both significantly associated with increased odds of clinically significant depressive symptoms. Our additional analysis, with only cisgender men, showed that, after adjusting for factors associated with clinically significant depressive symptoms, sexual discrimination was marginally associated with increased odds of clinically significant depressive symptoms among Latino sexual minority men $(\mathrm{AOR}=1.18,95 \% \mathrm{CI}=0.98-1.42, p<0.08)$.

\section{Discussion}

Overall, in this sample of Latino sexual minority men and Latina transgender women, we found high percentages of both ethnic/racial discrimination and sexual discrimination. Nearly three-quarters of participants $(73.7 \%)$ reported experiencing ethnic/racial discrimination and over half reported experiencing sexual discrimination (53.8\%). Further, over one-third (37.6\%) of the participants met the cut-off criterion for clinically significant depressive symptoms. In addition to masculinity, fatalism, and social support significantly associated with clinically significant depressive symptoms, we found both ethnic/racial discrimination and sexual discrimination were associated with increased odds of clinically significant depressive symptoms. These results underscore the need to consider the role of different types of discrimination on mental health.

The rate of perceived ethnic/racial discrimination was higher among this sample compared to a national sample of Latinos; in the 2010 National Survey of Latinos, 34\% of nativeborn and $33 \%$ of foreign-born Latinos reported that they or someone they know had experienced racial/ethnic discrimination in the past 5 years [50]. One potential reason for this difference is the particular context of the South and NC which includes a recent rapid growth in Latino populations, a lack of bilingual and bicultural infrastructure and resources, and greater hostility toward Latinos compared to states with longer histories of Latino immigration [3, 27-29].

The difference in experiences of perceived ethnic/racial discrimination and sexual discrimination may be understood by Goffman's [51] conceptualization of stigma. Stigma can be generated by more visible characteristics, such as ethnicity/ race, or less visible characteristics, such as sexual identity; this has implications for what characteristics can be hidden and when "passing" is possible, possibly reducing experiences of discrimination. For Latino sexual minority men and Latina transgender women, passing as heterosexual or cisgender may minimize some discrimination, thereby, reducing multiple marginalization that may incur from embodying multiple minority statuses. When navigating mental and other healthcare services, the implications of passing can vary. On one hand, passing may be a coping strategy that decreases direct discrimination experiences; on the other hand, it may serve to hide or conceal one's identity, which can lead to stress and depression [32].

The significant association between both ethnic/racial discrimination and sexual discrimination and clinically significant depressive symptoms are similar to other studies [52]. When the analysis of the association between sexual discrimination and clinically significant depressive symptoms was limited to a subsample of cisgender men, the magnitude and direction of the association remained similar, but the statistical significance was reduced. Sexual discrimination scores between Latino sexual minority men and Latina transgender women were not significantly different (results not shown). Taken together, this suggests that, by limiting the sample size to 150 , we may have reduced statistical power.

These results have several implications. Health practitioners should be aware of how discrimination is associated with clinically significant depressive symptoms and the need for culturally congruent mental health services for Latinos. A dearth of mental health services exists in new Latino settlement states like NC [53]. This is particularly problematic given that Latinos face many health access barriers, including mistrust, and thus may avoid seeking services that do exist [54]; this is especially true for Latino sexual minority men and Latina transgender women [55]. Our findings reinforce that more bilingual and bicultural mental health resources are needed that are accessible and consider factors such as discrimination, masculinity, fatalism, and social support. Thus, multilevel interventions should address pertinent individual, 
TABLE 2: Bivariable and multivariable associations with clinically significant depressive symptoms.

\begin{tabular}{|c|c|c|c|}
\hline & OR $(95 \% \mathrm{CI})$ & $\operatorname{AOR}(95 \% \mathrm{CI})^{\mathrm{a}, \mathrm{b}}$ & $\operatorname{AOR}(95 \% \mathrm{CI})^{\mathrm{a}, \mathrm{c}}$ \\
\hline \multicolumn{4}{|l|}{ Discrimination } \\
\hline Ethnic/racial & $1.28(1.13,1.45)^{\dagger}$ & $1.24(1.05,1.46)^{\dagger}$ & - \\
\hline Sexual identity or same-sex sexual behavior & $1.24(1.09,1.41)^{\dagger}$ & - & $1.22(1.03,1.44)^{\dagger}$ \\
\hline \multicolumn{4}{|l|}{ Control variables } \\
\hline Age (years) & $0.97(0.92,1.01)^{\ddagger}$ & $0.99(0.93,1.04)$ & $0.99(0.93,1.05)$ \\
\hline Employment status (year-round) & $0.54(0.26,1.11)^{\ddagger}$ & $1.56(0.56,4.36)$ & $1.49(0.54,4.11)$ \\
\hline Masculinity & $1.03(0.99,1.07)^{\ddagger}$ & $1.04(0.99,1.09)^{\ddagger}$ & $1.04(0.99,1.08)^{\ddagger}$ \\
\hline Fatalism & $1.03(1.00,1.05)^{\ddagger}$ & $1.03(1.00,1.06)^{\ddagger}$ & $1.03(1.00,1.06)^{\ddagger}$ \\
\hline Social support & $0.98(0.96,1.00)^{\ddagger}$ & $0.98(0.96,1.01)^{\ddagger}$ & $0.98(0.96,1.01)^{\ddagger}$ \\
\hline \multicolumn{4}{|l|}{ Other sociodemographics } \\
\hline Length of time lived in the US (years) & $0.98(0.92,1.04)$ & - & - \\
\hline$\geq$ HS diploma or equivalent & $0.73(0.37,1.43)$ & - & - \\
\hline$\geq \$ 2,000$ monthly income & $0.76(0.34,1.74)$ & - & - \\
\hline Alcohol use (days/week) & $0.80(0.53,1.20)$ & - & - \\
\hline Acculturation & $0.82(0.50,1.33)$ & - & - \\
\hline Internalized homonegativity & $0.99(0.95,1.03)$ & - & - \\
\hline Community attachment & $0.98(0.91,1.06)$ & - & - \\
\hline
\end{tabular}

${ }^{\ddagger} p<0.25$ and ${ }^{\dagger} p<0.05 .{ }^{a}$ Adjusted for age, employment status, masculinity, fatalism, and social support. ${ }^{b}$ Model to examine the association between ethnic/racial discrimination and clinically significant depressive symptoms. ${ }^{c}$ Model to examine the association between sexual discrimination and clinically significant depressive symptoms.

interpersonal, and system level factors that impact the careseeking behaviors of multimarginalized populations.

Multilevel interventions to reduce clinically significant depressive symptoms and increase access to mental health services may involve increasing social support and addressing masculinity and fatalism. As demonstrated in these results and other research, social support can be a protective factor to reduce the odds of depression [56, 57]; additional research about sexual and gender identity minorities' social networks may provide important information about sources of social support to inform interventions. These results also showed that masculinity and fatalism were associated with increased odds of clinically significant depressive symptoms and interventions that address both factors may be an important component to enhance coping strategies to promote mental health.

Several limitations should be taken into account. The results of this analysis are based on cross-sectional data and causal inferences are not possible. Prospective studies have found a similar association, where experience of discrimination at an earlier time point was positively associated with depression at a later time point and not vice versa $[20,58,59]$. Participants were asked to recall experiences of discrimination that occurred in the past 12 months, and accurate recall of events may have been challenged. This small sample consisted of Latino sexual minority men and Latina transgender women who were willing to participate in the HOLA intervention and findings may not be generalizable; however, whereas this was a relatively small sample of willing participants, this is also a hard-to-reach population. Future research should include qualitative research to further understand how and when Latino sexual minority men and Latina transgender women experience various types of discrimination and to identify other possible mechanisms to temper the association between discrimination and clinically significant depressive symptoms.

\section{Conclusion}

Latino sexual minority men and Latina transgender women living in the South, experience profound ethnic/racial discrimination and sexual discrimination that are linked with clinically significant levels of depressive symptoms. This study points to the importance of external factors, including discrimination and social support, on mental health outcomes for multimarginalized persons. Efforts to improve mental health require multilevel interventions that address pertinent individual (e.g., counseling services), interpersonal (e.g., social support groups), and system (e.g., accessibility of bilingual and bicultural mental healthcare) level factors and consider the particular context in which they navigate their care-seeking behaviors. Addressing these factors can enhance access to mental health and other services and reduce the mental health burden for marginalized populations, such as Latino sexual and gender identity minorities.

\section{Competing Interests}

The authors declare that they have no competing interests.

\section{Acknowledgments}

The authors sincerely thank the participants for their time and dedication. Support for this project was provided by the National Institute of Mental Health (R01MH087339). 


\section{References}

[1] US Census Bureau, "North Carolina fact sheet," 2014, http://www.census.gov/fastfacts/.

[2] S. R. Ennis, M. Rios-Vargas, and N. G. Albert, The Hispanic population: 2010, 2011, http://www.census.gov/prod/cen2010/briefs/ c2010br-04.pdf.

[3] R. Kochhar, R. Suro, and S. Tafoya, "The new Latino South: the context and consequences of rapid population growth," 2005, http://www.pewhispanic.org/2005/07/26/the-new-latino-south/.

[4] S. R. Potochnick and K. M. Perreira, "Depression and anxiety among first-generation immigrant latino youth: key correlates and implications for future research," The Journal of Nervous and Mental Disease, vol. 198, no. 7, pp. 470-477, 2010.

[5] Centers for Disease Control and Prevention, HIV among Latinos: fact sheet, 2013, http://www.cdc.gov/hiv/group/racialethnic/ hispaniclatinos/.

[6] S. D. Rhodes, O. Martinez, E.-Y. Song et al., "Depressive symptoms among immigrant Latino sexual minorities," American Journal of Health Behavior, vol. 37, no. 3, pp. 404-413, 2013.

[7] E. A. Pascoe and L. S. Richman, "Perceived discrimination and health: a meta-analytic review," Psychological Bulletin, vol. 135, no. 4, pp. 531-554, 2009.

[8] A. T. Ahmed, S. A. Mohammed, and D. R. Williams, "Racial discrimination and health: pathways and evidence," Indian Journal of Medical Research, vol. 126, no. 4, pp. 318-327, 2007.

[9] D. R. Williams and S. A. Mohammed, "Discrimination and racial disparities in health: evidence and needed research," Journal of Behavioral Medicine, vol. 32, no. 1, pp. 20-47, 2009.

[10] D. R. Byrd, "Race/ethnicity and self-reported levels of discrimination and psychological distress, California, 2005," Preventing Chronic Disease, vol. 9, no. 10, Article ID 120042, 2012.

[11] D. Burgess, A. Tran, R. Lee, and M. van Ryn, "Effects of perceived discrimination on mental health and mental health services utilization among gay, lesbian, bisexual and transgender persons," Journal of LGBT Health Research, vol. 3, no. 4, pp. 1-14, 2007.

[12] V. M. Mays and S. D. Cochran, "Mental health correlates of perceived discrimination among lesbian, gay, and bisexual adults in the United States," American Journal of Public Health, vol. 91, no. 11, pp. 1869-1876, 2001.

[13] S. D. Rhodes, K. C. Hergenrather, C. Zometa, K. Lindstrom, and J. Montaño, "Characteristics of immigrant Latino men who utilize formal healthcare services: baseline findings from the HoMBReS study," Journal of the National Medical Association, vol. 100, no. 10, pp. 1177-1185, 2008.

[14] S. D. Rhodes, L. J. Yee, and K. C. Hergenrather, "A communitybased rapid assessment of HIV behavioural risk disparities within a large sample of gay men in southeastern USA: a comparison of African American, Latino and white men," AIDS Care, vol. 18, no. 8, pp. 1018-1024, 2006.

[15] K.-H. Choi, J. Paul, G. Ayala, R. Boylan, and S. E. Gregorich, "Experiences of discrimination and their impact on the mental health among African American, Asian and Pacific Islander, and Latino men who have sex with men," American Journal of Public Health, vol. 103, no. 5, pp. 868-874, 2013.

[16] R. M. Díaz, G. Ayala, E. Bein, J. Henne, and B. V. Marin, “The impact of homophobia, poverty, and racism on the mental health of gay and bisexual Latino men: findings from 3 US cities," American Journal of Public Health, vol. 91, no. 6, pp. 927932, 2001.
[17] K. E. Gamarel, S. L. Reisner, J. T. Parsons, and S. A. Golub, "Association between socioeconomic position discrimination and psychological distress: findings from a community-based sample of gay and bisexual men in New York City," American Journal of Public Health, vol. 102, no. 11, pp. 2094-2101, 2012.

[18] B. Moradi and C. Risco, "Perceived discrimination experiences and mental health of Latina/o American persons," Journal of Counseling Psychology, vol. 53, no. 4, pp. 411-421, 2006.

[19] S. D. Cochran, V. M. Mays, M. Alegria, A. N. Ortega, and D. Takeuchi, "Mental health and substance use disorders among Latino and Asian American lesbian, gay, and bisexual adults," Journal of Consulting and Clinical Psychology, vol. 75, no. 5, pp. 785-794, 2007.

[20] M. L. Greene, N. Way, and K. Pahl, “Trajectories of perceived adult and peer discrimination among Black, Latino, and Asian American adolescents: patterns and psychological correlates," Developmental Psychology, vol. 42, no. 2, pp. 218-238, 2006.

[21] A. M. Ryan, G. C. Gee, and D. F. Laflamme, "The association between self-reported discrimination, physical health and blood pressure: findings from African Americans, Black immigrants, and Latino immigrants in New Hampshire," Journal of Health Care for the Poor and Underserved, vol. 17, no. 2, pp. 116132, 2006.

[22] R. M. Díaz, G. Ayala, and E. Bein, "Sexual risk as an outcome of social oppression: data from a probability sample of Latino gay men in three U.S. cities," Cultural Diversity \& Ethnic Minority Psychology, vol. 10, no. 3, pp. 255-267, 2004.

[23] F. T. Bianchi, M. C. Zea, P. J. Poppen, C. A. Reisen, and J. J. Echeverry, "Coping as a mediator of the impact of sociocultural factors on health behavior among HIV-positive Latino gay men," Psychology \& Health, vol. 19, no. 1, pp. 89-101, 2004.

[24] J. Ramirez-Valles, L. M. Kuhns, R. T. Campbell, and R. M. Diaz, "Social integration and health: community involvement, stigmatized identities, and sexual risk in latino sexual minorities," Journal of Health and Social Behavior, vol. 51, no. 1, pp. 30-47, 2010.

[25] E. M. Adams, B. J. Cahill, and S. J. Ackerlind, "A qualitative study of Latino lesbian and gay youths' experiences with discrimination and the career development process," Journal of Vocational Behavior, vol. 66, no. 2, pp. 199-218, 2005.

[26] D. M. Huebner, G. M. Rebchook, and S. M. Kegeles, "Experiences of harassment, discrimination, and physical violence among young gay and bisexual men," American Journal of Public Health, vol. 94, no. 7, pp. 1200-1203, 2004.

[27] C. Barrington, D. K. H. Messias, and L. Weber, "Implications of racial and ethnic relations for health and well-being in new Latino communities: a case study of West Columbia, South Carolina," Latino Studies, vol. 10, no. 1-2, pp. 155-178, 2012.

[28] S. D. Rhodes, F. M. Fernández, J. S. Leichliter et al., "Medications for sexual health available from non-medical sources: a need for increased access to healthcare and education among immigrant latinos in the rural Southeastern USA," Journal of Immigrant and Minority Health, vol. 13, no. 6, pp. 1183-1186, 2011.

[29] S. D. Rhodes, L. Mann, F. M. Simán et al., "The impact of local immigration enforcement policies on the health of immigrant Hispanics/Latinos in the United States," American Journal of Public Health, vol. 105, no. 2, pp. 329-337, 2015.

[30] M. P. Dentato, “The minority stress perspective," 2012, http:// www.apa.org/pi/aids/resources/exchange/2012/04/minoritystress.aspx.

[31] M. A. McCarthy, C. M. Fisher, J. A. Irwin, J. D. Coleman, and A. D. K. Pelster, "Using the minority stress model to understand 
depression in lesbian, gay, bisexual, and transgender individuals in nebraska," Journal of Gay \& Lesbian Mental Health, vol. 18, no. 4, pp. 346-360, 2014.

[32] I. H. Meyer, "Prejudice, social stress, and mental health in lesbian, gay, and bisexual populations: conceptual issues and research evidence," Psychological Bulletin, vol. 129, no. 5, pp. 674-697, 2003.

[33] S. D. Rhodes, J. Daniel, J. Alonzo et al., "A systematic community-based participatory approach to refining an evidencebased community-level intervention: the HOLA intervention for Latino men who have sex with men," Health Promotion Practice, vol. 14, no. 4, pp. 607-616, 2013.

[34] C. J. Sun, M. García, L. Mann, J. Alonzo, E. Eng, and S. D. Rhodes, "Latino sexual and gender identity minorities promoting sexual health within their social networks: process evaluation findings from a lay health advisor intervention," Health Promotion Practice, vol. 16, no. 3, pp. 329-337, 2015.

[35] S. D. Rhodes, L. Mann, J. Alonzo et al., "CBPR to prevent HIV within racial/ethnic, sexual, and gender minority communities: successes with long-term sustainability," in Innovations in HIV Prevention Research and Practice through Community Engagement, S. D. Rhodes, Ed., chapter 7, pp. 135-160, Springer, New York, NY, USA, 2014.

[36] M. C. O’Brien, T. P. McCoy, H. Champion et al., "Single question about drunkenness to detect college students at risk for injury," Academic Emergency Medicine, vol. 13, no. 6, pp. 629-636, 2006.

[37] G. Marin, F. Sabogal, B. V. Marin, R. Otero-Sabogal, and E. J. Perez-Stable, "Development of a short acculturation scale for Hispanics," Hispanic Journal of Behavioral Sciences, vol. 9, no. 2, pp. 183-205, 1987.

[38] J. R. Mahalik, B. D. Locke, L. H. Ludlow et al., "Development of the conformity to masculine norms inventory," Psychology of Men Masculinity, vol. 4, no. 1, pp. 3-25, 2003.

[39] D. J. Smolenski, P. M. Diamond, M. W. Ross, and B. R. S. Rosser, "Revision, criterion validity, and multigroup assessment of the reactions to homosexuality scale," Journal of Personality Assessment, vol. 92, no. 6, pp. 568-576, 2010.

[40] L. Shen, C. M. Condit, and L. Wright, "The psychometric property and validation of a fatalism scale," Psychology \& Health, vol. 24, no. 5, pp. 597-613, 2009.

[41] L. O’Donnell, G. Agronick, A. San Doval, R. Duran, A. Myint$\mathrm{U}$, and A. Stueve, "Ethnic and gay community attachments and sexual risk behaviors among urban Latino young men who have sex with men," AIDS Education and Prevention, vol. 14, no. 6, pp. 457-471, 2002.

[42] A. S. J. Ong and C. Ward, "The construction and validation of a social support measure for sojourners the Index of Sojourner Social Support (ISSS) scale," Journal of Cross-Cultural Psychology, vol. 36, no. 6, pp. 637-661, 2005.

[43] S. D. Rhodes, J. Daniel, E.-Y. Song, J. Alonzo, M. Downs, and B. A. Reboussin, "Social support among immigrant Latino men: a validation study," American Journal of Health Behavior, vol. 37, no. 5, pp. 620-628, 2013.

[44] D. R. Williams, Y. Yu, J. S. Jackson, and N. B. Anderson, "Racial differences in physical and mental health: socio-economic status, stress and discrimination," Journal of Health Psychology, vol. 2, no. 3, pp. 335-351, 1997.

[45] G. Kim, M. Sellbom, and K.-L. Ford, "Race/ethnicity and measurement equivalence of the everyday discrimination scale," Psychological Assessment, vol. 26, no. 3, pp. 892-900, 2014.
[46] L. S. Radloff, “The CES-D scale: a self-report depression scale for research in the general population," Applied Psychological Measurement, vol. 1, no. 3, pp. 385-401, 1977.

[47] P. M. Lewinsohn, J. R. Seeley, R. E. Roberts, and N. B. Allen, "Center for Epidemiologic Studies Depression Scale (CES-D) as a screening instrument for depression among communityresiding older adults," Psychology and Aging, vol. 12, no. 2, pp. 277-287, 1997.

[48] C. Bono, L. D. Ried, C. Kimberlin, and B. Vogel, "Missing data on the Center for Epidemiologic Studies Depression Scale: a comparison of 4 imputation techniques," Research in Social and Administrative Pharmacy, vol. 3, no. 1, pp. 1-27, 2007.

[49] D. W. Hosmer and S. Lemeshow, Applied Logistic Regression, John Wiley \& Sons, New York, NY, USA, 1989.

[50] M. Hugo Lopez, R. Morin, and P. Taylor, "Illegal Immigration Backlash Worries, Divides Latinos," http://www.pewhispanic .org/2010/10/28/illegal-immigration-backlash-worries-divideslatinos/.

[51] E. Goffman, Stigma: Notes on the Management of Spoiled Identity, Prentice Hall, Englewood Cliffs, NJ, USA, 1963.

[52] L. Torres and A. D. Ong, "A daily diary investigation of latino ethnic identity, discrimination, and depression," Cultural Diversity \& Ethnic Minority Psychology, vol. 16, no. 4, pp. 561568, 2010.

[53] B. Ball, Immigrants denied mental health services, 2013, http://www.indyweek.com/indyweek/immigrants-deniedmental-health-services/Content?oid $=3428766$.

[54] M. M. Shattell, D. Hamilton, S. S. Starr, C. J. Jenkins, and N. A. Hinderliter, "Mental health service needs of a Latino population: a community-based participatory research project," Issues in Mental Health Nursing, vol. 29, no. 4, pp. 351-370, 2008.

[55] A. E. Tanner, B. A. Reboussin, L. Mann et al., "Factors influencing health care access perceptions and care-seeking behaviors of immigrant Latino sexual minority men and transgender individuals: baseline findings from the HOLA intervention study," Journal of Health Care for the Poor and Underserved, vol. 25, no. 4, pp. 1679-1697, 2014.

[56] J. Almeida, S. V. Subramanian, I. Kawachi, and B. E. Molnar, "Is blood thicker than water? Social support, depression and the modifying role of ethnicity/nativity status," Journal of Epidemiology \& Community Health, vol. 65, no. 1, pp. 51-56, 2011.

[57] F. I. Rivera, "Contextualizing the experience of young latino adults: acculturation, social support and depression," Journal of Immigrant and Minority Health, vol. 9, no. 3, pp. 237-244, 2007.

[58] T. N. Brown, D. R. Williams, J. S. Jackson et al., "'Being black and feeling blue': the mental health consequences of racial discrimination," Race and Society, vol. 2, no. 2, pp. 117-131, 2000.

[59] A. J. Schulz, B. A. Israel, S. N. Zenk et al., "Psychosocial stress and social support as mediators of relationships between income, length of residence and depressive symptoms among African American women on Detroit's eastside," Social Science \& Medicine, vol. 62, no. 2, pp. 510-522, 2006. 


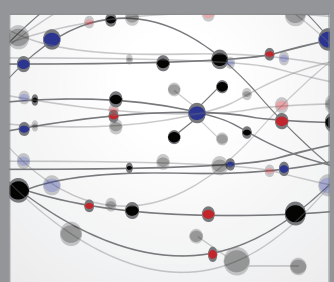

The Scientific World Journal
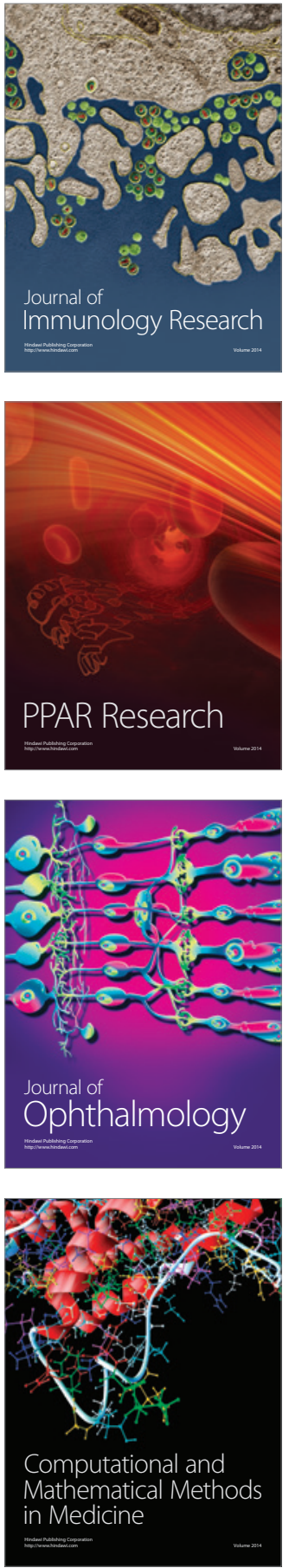

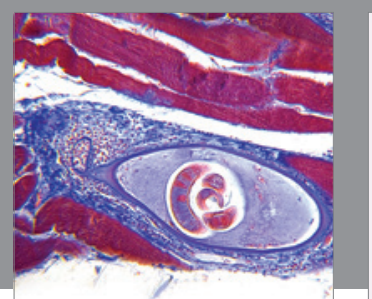

Gastroenterology Research and Practice

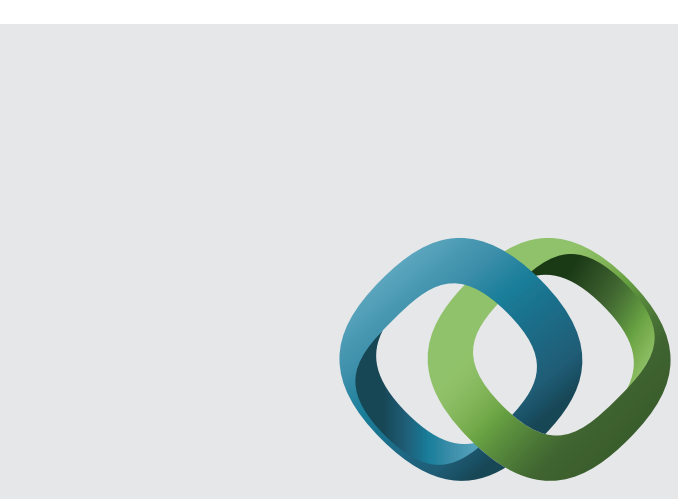

\section{Hindawi}

Submit your manuscripts at

http://www.hindawi.com
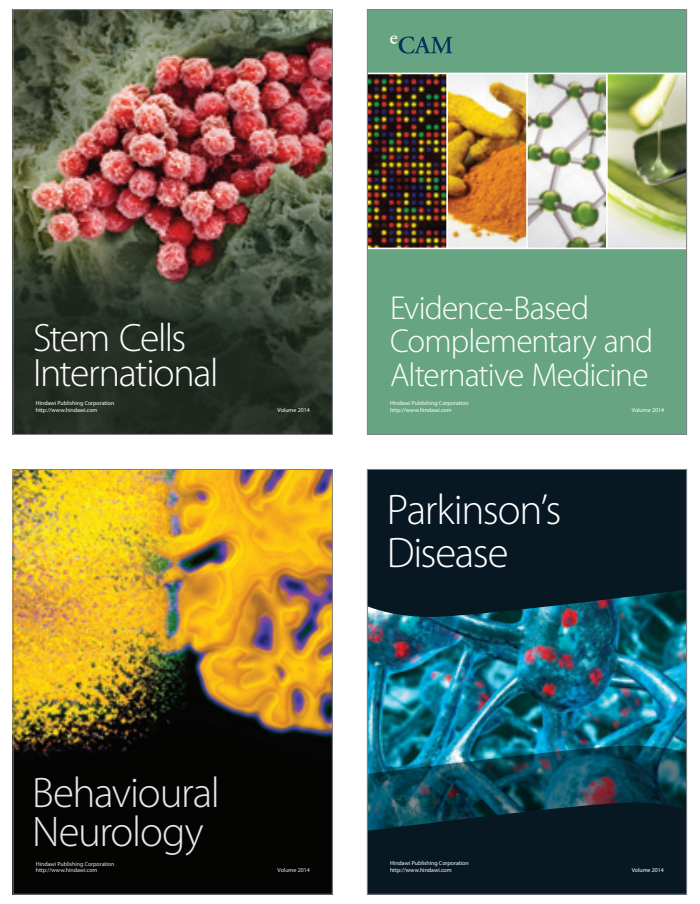
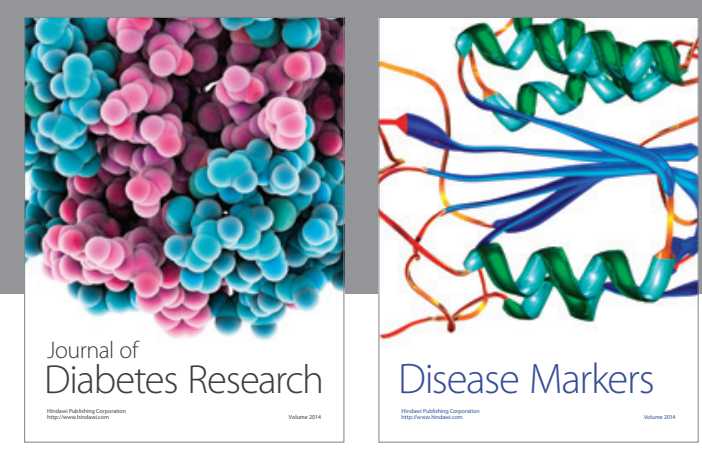

Disease Markers
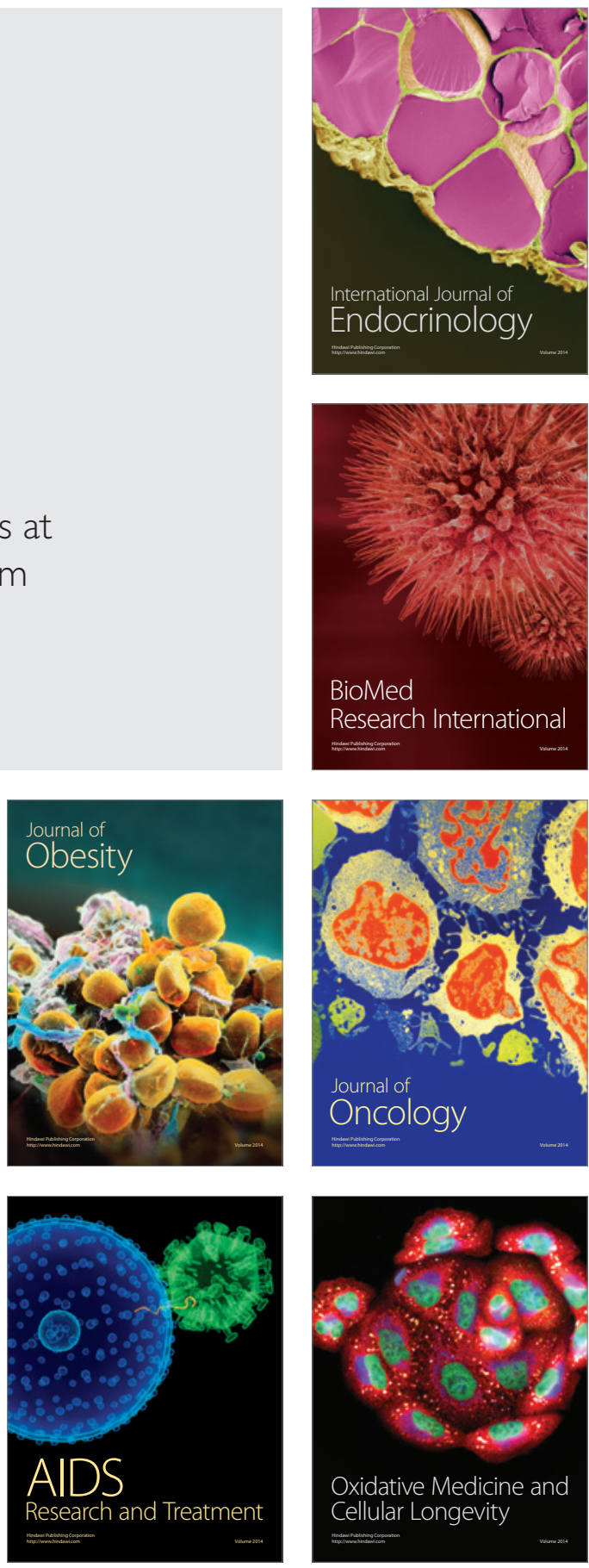